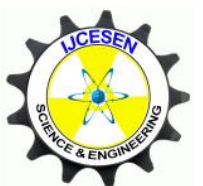

Copyright (C) IJCESEN
International Journal of Computationaland

Experimental $\boldsymbol{S}$ cienceand $\boldsymbol{E} \boldsymbol{N}$ gineering

(IJCESEN)

Vol. 5-No.2 (2019) pp. 86-93

http://dergipark.org.tr/ijcesen

ResearchArticle

\title{
Environmental Radiation Doses from Patients Undergoing Tc-99m DMSA Cortical Renal Scintigraphy
}

\author{
Osman GÜNAY ${ }^{1 *}$, Mucize SARIHAN ${ }^{1}$, Evrim ABAMOR $^{2}$, Onur YARAR $^{1}$ \\ ${ }^{1}$ Istanbul Okan University, Vocational School of Health Services, Istanbul,Turkey \\ ${ }^{2}$ University of Health Science, Kartal Dr. Lütfi Kırdar Education and Research Hospital, Departmant of Nuclear \\ Medicine ,Istanbul Turkey \\ * Corresponding Author : osman.gunay@okan.edu.tr \\ ORCID: 0000-0003-0760-554X
}

\section{ArticleInfo:}

DOI: $10.22399 /$ ijcesen.589267

Received : 09 July 2019

Accepted : 28 July 2019

\section{Keywords}

DMSA

Radiation Dose

Tc-99m

\begin{abstract}
:
Ionizing radiation is often used for imaging in health applications. One of them is scintigraphic method. one of the radiation emitters used in nuclear medicine is technesium-99m (Tc-99m). This isotope releases gamma rays at about the same wavelength as conventional X-ray diagnostic equipment, with $140 \mathrm{keV}$ gamma ray energy which has a ideal short half-life $\left(t_{1 / 2}=6 \mathrm{~h}\right)$ for diagnostic nuclear imaging. Before imaging, the patient is injected with Tc-99m. After injecting Tc-99m, the patient begins to emit radiation to the environment. Determination of this radiation dose emitted by the patient is very important for public health. The main objective of this study was to determine the environmental radiation doses in patients undergoing Tc-99m DMSA cortical renal scintigraphy. In this study, the radiation dose rate emitted by the patient about 5, 35 and 68 minutes after Tc-99m injection was measured at different distances from the patient. As a result of this study, the mean radiation dose at 5.07, 35.60 and 68.57 minutes after injection was found to be $5.06 \mu \mathrm{Svh}^{-1}, 4.76 \mu \mathrm{Svh}^{-1}$ and $4.18 \mu \mathrm{Svh}^{-1}$ at a distance of $100 \mathrm{~cm}$ from the patient's chest level, respectively. The results are important in terms of knowing the radiation dose to which the patient will be exposed.
\end{abstract}

\section{Introduction}

People are constantly exposed to natural radiation throughout their lives. However, in some cases they may be exposed to artificial radiation. Most of the artificial radiation exposed to the population is due to medical applications. Determination of the radiation level in medical applications is a prerequisite for radiation protection in public health. In recent years, many studies have been conducted to determine the radiation level in medical applications.

Technetium-99m (Tc-99m) is the most commonly used radionuclide in nuclear medicine for diagnostic imaging in order to evaluate disease state as well as to monitor the effects of treatments. This isotope releases gamma rays at about the same wavelength as conventional X-ray diagnostic equipment, with $140 \mathrm{keV}$ gamma ray energy which has a ideal short half-life $\left(t_{1 / 2}=6 \mathrm{~h}\right)$ for diagnostic nuclear imaging. Patients can be injected with a small amount of Tc-99m and within $24 \mathrm{~h}$ almost $94 \%$ of the injected radionuclide would have decayed and left the body, limiting the patient's radiation exposure [1]. During this time patient also radiates gamma ray environmental radiation to accompanying persons near the patient and to nuclear medicine workers. Tc-99m is chemically bounded to various bioactive chemical substances, producing radiopharmaceuticals which are used for functional imaging of many organs. When Tc-99m bounded to Dimercaptosuccinic acid (DMSA) which is an antidote to heavy metal toxicity, composed Tc-99m Dimercaptosuccinic acid (Tc99m DMSA) is used for static renal imaging of renal cortical structure. The tracer is concentrated 
in the proximal tubular cells of the kidney. Tc-99m DMSA enters the proximal tubular cell either by glomerular filtration and subsequent reabsorption or by direct uptake from the peritubular capillaries [2]. As Tc-99m DMSA is largely bound to serum proteins [3]. it is accepted as the glomerular filtration is insignificant and uptake occurs at peritubular side of the cell [4]. By the uptake mechanism Tc-99m DMSA is fixed in renal cortex showing renal parenchymal integrity or damage. Scintigraphy with Tc-99m DMSA is in favour as a reference method for the assessment of renal parenchymal lesions and estimation of differential renal function [5]. Urinary tract infection (UTI) is a relatively frequent disease in children even in new born and young babies as well in diabetic individuals with increased risk of paranchymal damage and renal scarring [6-7] Renal cortical scintigraphy with Tc-99m DMSA has been accepted as "gold standard" for renal cortical scarring imaging for many years [8]. Renal cortical scintigraphy with Tc-99m DMSA is the method of choice to detect acute pyelonephritis and cortical scarring. It is mostly used in children with urinary tract infection safely, even in young babies with low doses [9]. Tc-99m DMSA intravenous given doses in adults is about 4-5 mCi (about $185 \mathrm{MBq}$ ) and it is calculated in children according to child dose algoritmas [10]. The effective radiation dose and the dose received by the organs after intravenous administration of Tc-99m DMSA in adult and child patients is documented [11-12].

Patients are imaged after 2 to 4 hours after the administration of Tc-99m DMSA. During this waiting time and during imaging procedure, patients are accompanied by nuclear medicine workers and children are also accompanied by their parents or caregivers. After imaging procedure completed, patients leave the department. Adults are warned to keep far away from public and their close contacts at least 24 hours but especially children are accompanied by their parents or caregivers. Both nuclear medicine workers and patient accompanying people receive external radiation overspread from patient to environment. Although patient received effective and organ doses for Tc99-m DMSA are well documented in the literature, the external radiation doses spreading from patient to peripheric region and accompanying persons are not well examined.

We tried to analyze environmental radiation doses from patients undergoing Tc-99m DMSA cortical renal scintigraphy, taking in consideration that most of the patients are in little childhood who need close care of their parents, relatives or nursery maid.

\section{Materials and Methods}

This study was performed in 24 (11 female and 13 male) randomly selected patients at Okan University hospital in Istanbul. The ages of the patients were varied range from 4 to 88 years, with a mean age of 40.12 years. The patients' weights were varied range from 18 to $102 \mathrm{~kg}$ and their average weight was $64.68 \mathrm{~kg}$. The patients were given radioactivity according to the protocols of Istanbul Okan University. The amounts of radioactivity vary according to the weight of the patient. The mounts of radioactivity injected into patients were varied range from 103.62 $\mathrm{MBq}$ to $203.58 \mathrm{MBq}$, with an average of $168.61 \mathrm{MBq}$. Exposure rate due to radiation emitted from the patient was measured approximately 5 minutes, 35 minutes and 68 minutes after injection of radioactive material. The radiation dose rate was measured at twelve locations for patients. Headlevel radiation dose rate measurements were made at a distance of $25 \mathrm{~cm}$ (anterior), $50 \mathrm{~cm}$ (anterior), $100 \mathrm{~cm}$ (anterior) and 200 (anterior) $\mathrm{cm}$ from the patient's head. Foot-level and chest-level measurements were also made at the same distance points of $25 \mathrm{~cm}, 50 \mathrm{~cm}, 100 \mathrm{~cm}$ and $200 \mathrm{~cm}$ from the patient's chest and foot level (Fig. 1). GM counter (Inspector Nuclear Radiation Monitor Deluxe Dose Rate CPT.5250-0047) used in radiation dose rate measurements. Calibration (Inspector Nuclear Radiation Monitor Deluxe Dose Rate CPT.5250-0047) was done by Turkish Atom Energy Association in June 2018. Informed consent was obtained from all participants included in the study according to the approval of Istanbul Okan University, Research Ethics Committee.

\section{Results and Discussion}

The amount of radioactivity injected into the patient varies according to the patient's weight. The radiation emitted from the patient varies according to the amount of radioactivity given to the patient. The amount of radioactivity injected into all patients varied range from 103.61 to $203.57 \mathrm{MBq}$, with an average of $168.61 \mathrm{MBq}$. At 5.07, 35.60 and 68.57 minutes after injection, the average radiation dose rate at different distances from the patient's head level is shown in table 1 . In addition, the radiation dose rate measurement range and normalized dose rate are also shown in Table 1. At 5.07, 35.60 and 68.57 minutes after injection, 


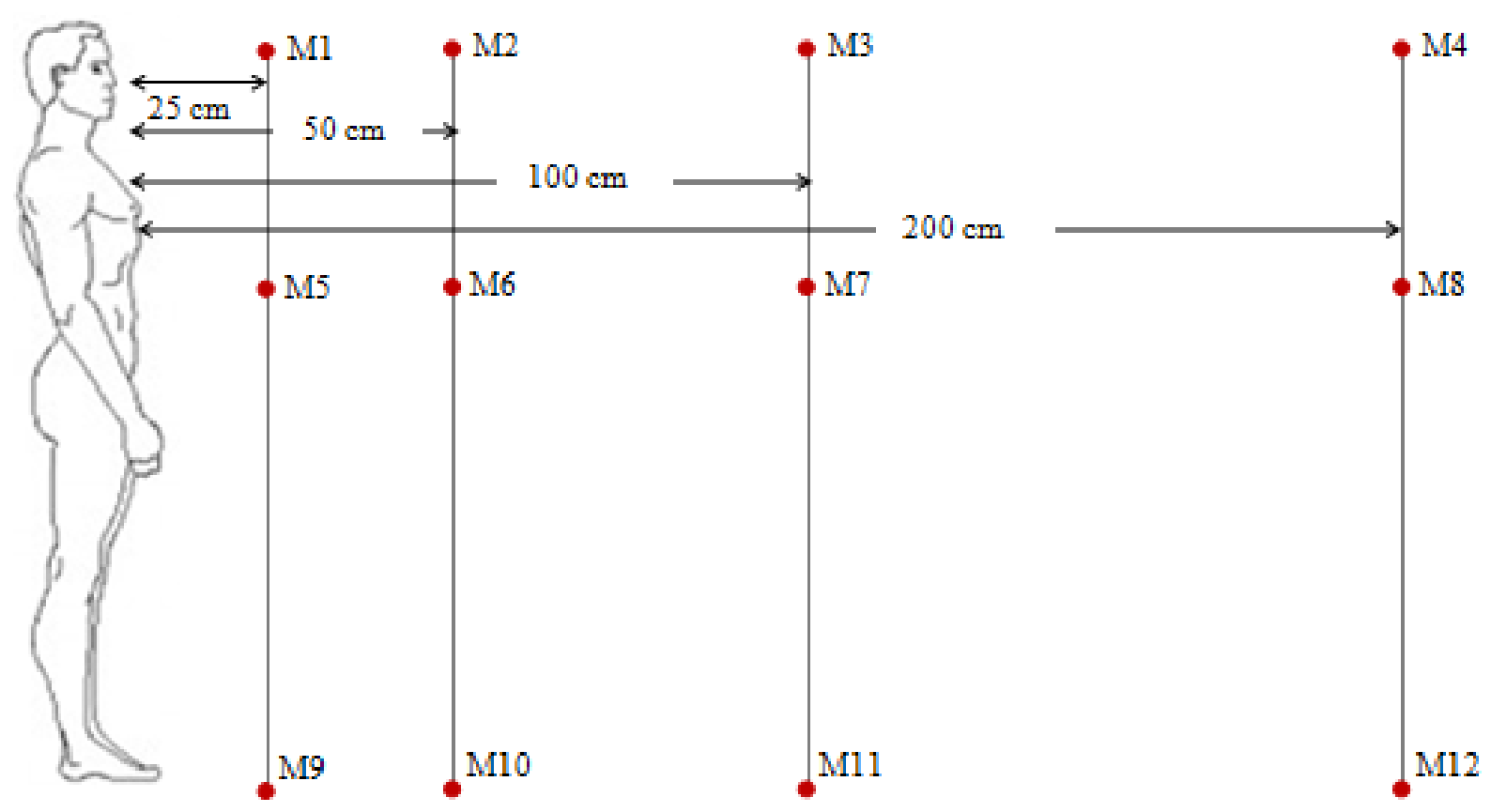

Figure 1.TLD locations in CT imaging (1,2,3 and 4 points are representing $10 \mathrm{~cm}, 20 \mathrm{~cm}, 30 \mathrm{~cm}$ and $40 \mathrm{~cm}$ from the origin point, respectively)

average radiation dose rate at a distance of $100 \mathrm{~cm}$ from the patient's head level are $5.47 \mu \mathrm{Svh}^{-1}, 4.53$ $\mu \mathrm{Svh}^{-1}$ and $4.41 \mu \mathrm{Svh}^{-1}$ respectively. At 5.07, 35.60 and 68.57 minutes after injection, the average radiation dose rate at different distances from the patient's chest level is shown in table 2 .

Table 1. Mean Dose Rate and Normalized Dose Rate for

\begin{tabular}{|c|c|c|c|c|}
\hline \multicolumn{5}{|c|}{ Different Distance from Head } \\
\hline $\begin{array}{l}\text { Location } \\
\text { (Distance } \\
\text { from } \\
\text { patient) } \\
\text { (cm) }\end{array}$ & $\begin{array}{l}\text { Time } \\
\text { after the } \\
\text { injection } \\
\text { (min) }\end{array}$ & $\begin{array}{l}\text { Mean } \\
\text { Dose } \\
\text { Rate } \\
\left(\mu \operatorname{Svh}^{-1}\right)\end{array}$ & $\begin{array}{l}\text { Dose } \\
\text { Rate } \\
\text { Range } \\
\left(\mu \mathrm{Svh}^{-1}\right)\end{array}$ & $\begin{array}{l}\text { Normalized } \\
\text { Mean Dose } \\
\text { Rate }\left(\mu S v h^{-}\right. \\
\left.{ }^{1} \mathrm{MBq}^{-1}\right)\end{array}$ \\
\hline \multirow{3}{*}{25} & 5.07 & 20.59 & $5.12-31.56$ & 0.123 \\
\hline & 35.60 & 16.76 & $3.89-26.98$ & 0.100 \\
\hline & 68.57 & 13.47 & $3.13-27.09$ & 0.080 \\
\hline \multirow{3}{*}{50} & 5.07 & 9.00 & $5.64-12.46$ & 0.054 \\
\hline & 35.60 & 7.53 & $4.73-11.35$ & 0.045 \\
\hline & 68.57 & 7.00 & $4.32-10.73$ & 0.042 \\
\hline \multirow{3}{*}{100} & 5.07 & 5.47 & $3.96-8.45$ & 0.033 \\
\hline & 35.60 & 4.53 & $3.47-7.12$ & 0.027 \\
\hline & 68.57 & 4.41 & $3.12-6.31$ & 0.026 \\
\hline \multirow{3}{*}{200} & 5.07 & 3.35 & $2.93-5.42$ & 0.020 \\
\hline & 35.60 & 3.47 & $2.54-6.01$ & 0.021 \\
\hline & 68.57 & 2.88 & $1.35-4.33$ & 0.017 \\
\hline
\end{tabular}

Table 2. Mean Dose Rate and Normalized Dose Rate for Different Distance from Chest

\begin{tabular}{|c|c|c|c|c|}
\hline \multicolumn{5}{|c|}{ Different Distance from Chest } \\
\hline $\begin{array}{l}\text { Location } \\
\text { (Distanc } \\
\text { e from } \\
\text { patient) } \\
\text { (cm) }\end{array}$ & $\begin{array}{l}\text { Time } \\
\text { after the } \\
\text { injectio } \\
\text { n (min) }\end{array}$ & $\begin{array}{l}\text { Mean } \\
\text { Dose } \\
\text { Rate } \\
\left(\mu S v{ }^{-}\right. \\
1)\end{array}$ & $\begin{array}{l}\text { Dose } \\
\text { Rate } \\
\text { Range } \\
\left(\mu \mathrm{Svh}^{-1}\right)\end{array}$ & $\begin{array}{l}\text { Normalize } \\
\text { d Mean } \\
\text { Dose Rate } \\
\left(\mu \mathrm{Svh}^{-1}\right. \\
\left.\mathrm{MBq}^{-1}\right)\end{array}$ \\
\hline \multirow{3}{*}{25} & 5.07 & 52.59 & $\begin{array}{l}23.87- \\
111.13\end{array}$ & 0.313 \\
\hline & 35.60 & 39.06 & $\begin{array}{c}17.64- \\
63.87\end{array}$ & 0.232 \\
\hline & 68.57 & 36.35 & $4.95-52.31$ & 0.216 \\
\hline \multirow{3}{*}{50} & 5.07 & 11.24 & $6.89-18.97$ & 0.067 \\
\hline & 35.60 & 9.76 & $6.51-18.64$ & 0.058 \\
\hline & 68.57 & 9.29 & $6.12-17.53$ & 0.055 \\
\hline \multirow{3}{*}{100} & 5.07 & 5.06 & $3.58-7.96$ & 0.030 \\
\hline & 35.60 & 4.76 & $3.14-6.98$ & 0.028 \\
\hline & 68.57 & 4.18 & $3.03-7.02$ & 0.025 \\
\hline \multirow{3}{*}{200} & 5.07 & 2.65 & $1.97-4.75$ & 0.016 \\
\hline & 35.60 & 2.65 & $1.63-5.03$ & 0.016 \\
\hline & 68.57 & 2.24 & $1.26-3.83$ & 0.013 \\
\hline
\end{tabular}

In addition, the radiation dose rate measurement range and normalized dose rate are also shown in Table 1. At 5.07, 35.60 and 68.57 minutes after injection, average radiation dose rate at a distance 
of $100 \mathrm{~cm}$ from the patient's chest level are 5.06 $\mu \mathrm{Svh}^{-1}, 4.76 \mu \mathrm{Svh}^{-1}$ and $4.18 \mu \mathrm{Svh}^{-1}$ respectively. At 5.07, 35.60 and 68.57 minutes after injection, the average radiation dose rate at different distances from the patient's foot level is shown in table 3. In addition, the radiation dose rate measurement range and normalized dose rate are also shown in Table 3. At 5.07, 35.60 and 68.57 minutes after injection, average radiation dose rate at a distance of $100 \mathrm{~cm}$ from the patient's foot level are $4.35 \mu \mathrm{Svh}^{-1}, 4.24$ $\mu \mathrm{Svh}^{-1}$ and $3.71 \mu \mathrm{Svh}^{-1}$ respectively. The radiation dose rate at $25 \mathrm{~cm}$ from the patient's head, chest and foot level is shown in figure 2. In this figure, it is seen that as the time increases, the mean radiation dose rates decreases. At the head and foot level, there is a strong correlation between mean radiation dose rates and time at a distance of $25 \mathrm{~cm}$ from the patient. But, at chest level, there is a moderate correlation. The correlation coefficient at head, chest and foot level is $\mathrm{R}^{2}=1, \mathrm{R}^{2}=0.875$ and $\mathrm{R}^{2}=0.943$ respectively. The radiation dose rate at 50 $\mathrm{cm}$ from the patient's head, chest and foot level is shown in figure 3 . In this figure, it is seen that as the time increases, the mean radiation dose rates decreases. At the head, chest and foot level, there is a strong correlation between mean radiation dose rates and time at a distance of $50 \mathrm{~cm}$ from the patient. The correlation coefficient at head, chest and foot level is $R^{2}=0.933, R^{2}=0.917$ and $R^{2}=0.931$ respectively.

The radiation dose rate at $100 \mathrm{~cm}$ from the patient's head, chest and foot level is shown in figure 4 . In this figure, it is seen that as the time increases, the mean radiation dose rates decreases. At the chest and foot level, there is a correlation between mean radiation dose rates and time at a distance of 100 $\mathrm{cm}$ from the patient. But at the head level, there is a moderate correlation. The correlation coefficient at head, chest and foot level is $\mathrm{R}^{2}=0.823, \mathrm{R}^{2}=0.963$ and $\mathrm{R}^{2}=0.887$ respectively. The radiation dose rate at $200 \mathrm{~cm}$ from the patient's head, chest and foot level is shown in figure 5. In this figure, it is seen that as the time increases, the mean radiation dose rates decreases.

Table 3. Mean Dose Rate and Normalized Dose Rate for Different Distance from Foot

\begin{tabular}{|c|c|c|c|c|}
\hline $\begin{array}{l}\text { Location } \\
\text { (Distance } \\
\text { from } \\
\text { patient) } \\
\text { (cm) }\end{array}$ & $\begin{array}{l}\text { Time } \\
\text { after the } \\
\text { injection } \\
(\text { min) }\end{array}$ & $\begin{array}{l}\text { Mean } \\
\text { Dose } \\
\text { Rate } \\
\left(\mu S v{ }^{-}\right. \\
\left.{ }^{1}\right)\end{array}$ & $\begin{array}{l}\text { Dose } \\
\text { Rate } \\
\text { Range } \\
\left(\mu \mathrm{Svh}^{-1}\right)\end{array}$ & $\begin{array}{l}\text { Normalized } \\
\text { Mean Dose } \\
\text { Rate }\left(\mu \mu^{\mu}{ }^{-}\right. \\
\left.{ }^{1} \mathbf{M B q}^{-1}\right)\end{array}$ \\
\hline \multirow{3}{*}{25} & 5.07 & 11.12 & $5.68-22.54$ & 0.066 \\
\hline & 35.60 & 9.82 & $4.93-41.16$ & 0.058 \\
\hline & 68.57 & 7.00 & $3.98-13.54$ & 0.042 \\
\hline \multirow{3}{*}{50} & 5.07 & 7.35 & $3.87-11.52$ & 0.044 \\
\hline & 35.60 & 7.24 & $4.33-10.86$ & 0.043 \\
\hline & 68.57 & 6.88 & $4.12-10.21$ & 0.041 \\
\hline \multirow{3}{*}{100} & 5.07 & 4.35 & $3.57-6.97$ & 0.026 \\
\hline & 35.60 & 4.24 & $2.94-6.53$ & 0.025 \\
\hline & 68.57 & 3.71 & $2.51-6.32$ & 0.022 \\
\hline \multirow{3}{*}{200} & 5.07 & 2.29 & $1.84-3.52$ & 0.014 \\
\hline & 35.60 & 2.12 & $1.62-3.37$ & 0.013 \\
\hline & 68.57 & 1.76 & $1.12-3.01$ & 0.011 \\
\hline
\end{tabular}

At the head and chest level, there is a moderate correlation between mean radiation dose rates and time at a distance of $200 \mathrm{~cm}$ from the patient. But at the foot level, there is a strong correlation.

$25 \mathrm{~cm}$

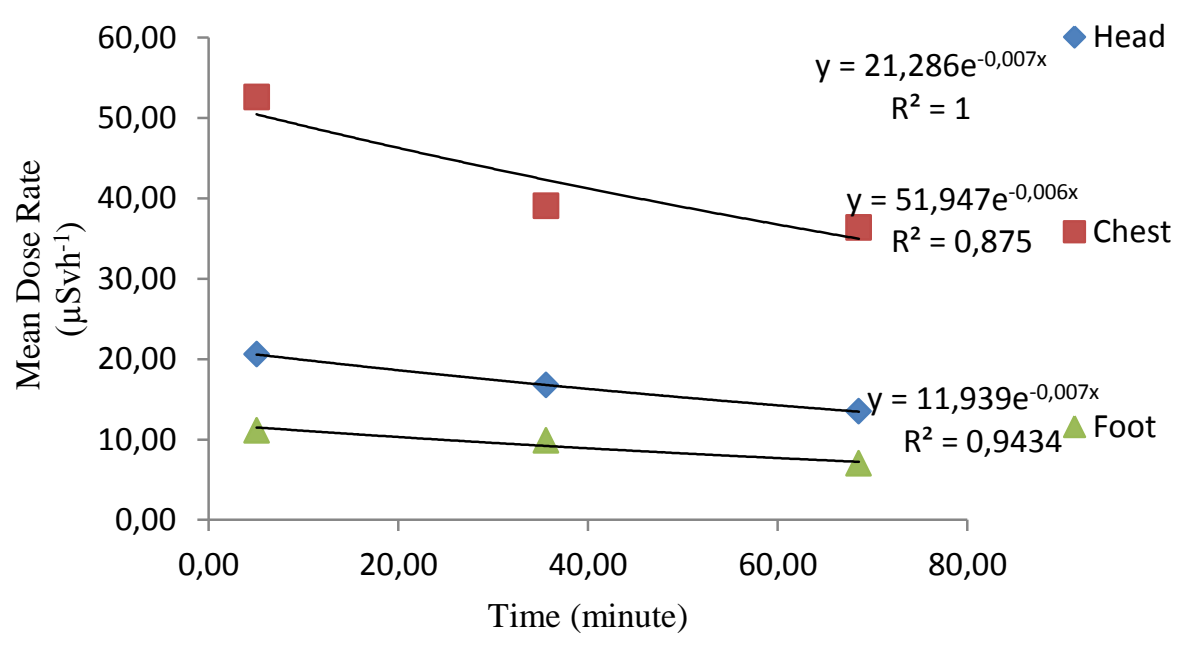

Figure 2. Mean dose rate by time $25 \mathrm{~cm}$ from the head, chest, and foot of the patient 


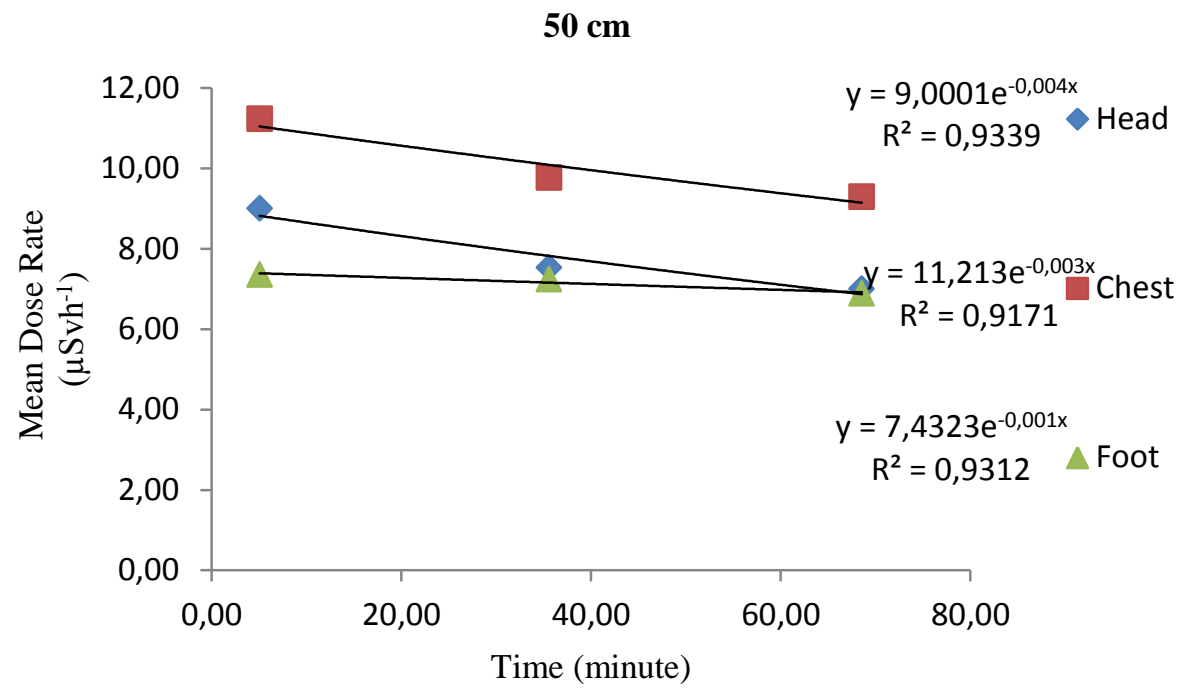

Figure 3. Mean dose rate by time $50 \mathrm{~cm}$ from the head, chest, and foot of the patient

$100 \mathrm{~cm}$

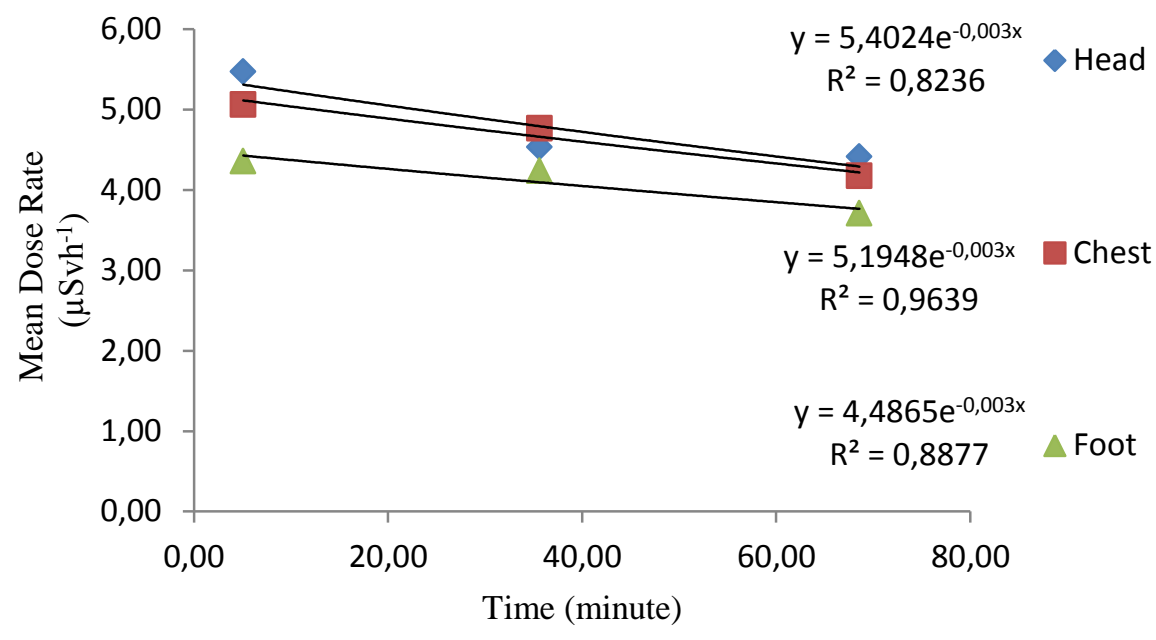

Figure 4. Mean dose rate by time $100 \mathrm{~cm}$ from the head, chest, and foot of the patient

The correlation coefficient at head, chest and foot level is $R^{2}=0.607, \quad R^{2}=0.768$ and $R^{2}=0.960$ respectively

At different times after injection, the average radiation dose rate against the distance from the patient's head level is shown in figure 6 . In this figure, as the distance from the patient increases, the average radiation dose rate decreases. There is a strong correlation between radiation dose rate and distance in 5.07, 35.60 and $68.57 \mathrm{~min}$. The correlation coefficient between the radiation dose rate and distance from the injection at $5.07 \mathrm{~min}$, $35.60 \mathrm{~min}$ and $68.57 \mathrm{~min}$ is $\mathrm{R}^{2}=0.981, \mathrm{R}^{2}=0.950$ and $R^{2}=0.989$ respectively.

At different times after injection, the average radiation dose rate against the distance from the patient's chest level is shown in figure 7. In this figure, as the distance from the patient increases, the average radiation dose rate decreases. There is a strong correlation between radiation dose rate and distance in 5.07, 35.60 and $68.57 \mathrm{~min}$. The correlation coefficient between the radiation dose rate and distance from the injection at $5.07 \mathrm{~min}$, $35.60 \mathrm{~min}$ and $68.57 \mathrm{~min}$ is $\mathrm{R}^{2}=0.956, \mathrm{R}^{2}=0.956$ and $R^{2}=0.966$ respectively.

At different times after injection, the average radiation dose rate against the distance from the patient's foot level is shown in figure 8. In this figure, as the distance from the patient increases, the average radiation dose rate decreases. There is a strong correlation between radiation dose rate and distance in $5.07 \mathrm{~min}$. But there is a moderate correlation between radiation dose rate and distance in 35.60 and $68.57 \mathrm{~min}$. The correlation coefficient between the radiation dose rate and distance from the injection at $5.07 \mathrm{~min}, 35.60 \mathrm{~min}$ and $68.57 \mathrm{~min}$ is $\mathrm{R}^{2}=0.902, \mathrm{R}^{2}=0.855$ and $\mathrm{R}^{2}=0.710$ respectively. 


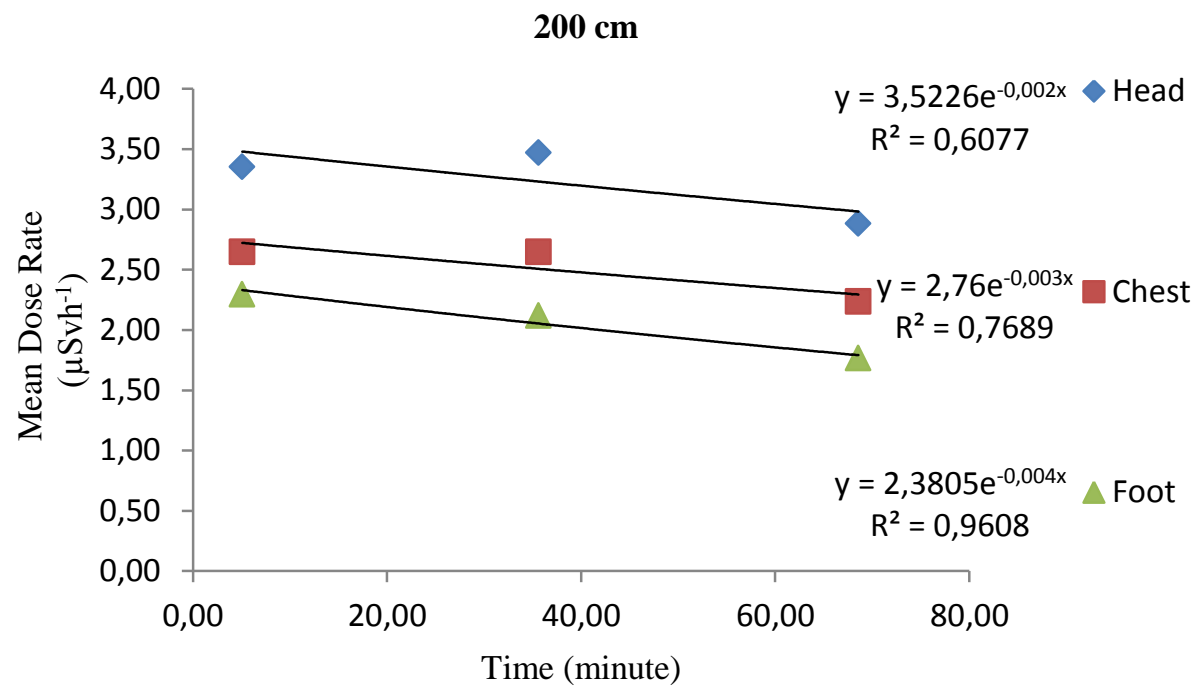

Figure 5. Mean dose rate by time $200 \mathrm{~cm}$ from the head, chest, and foot of the patient

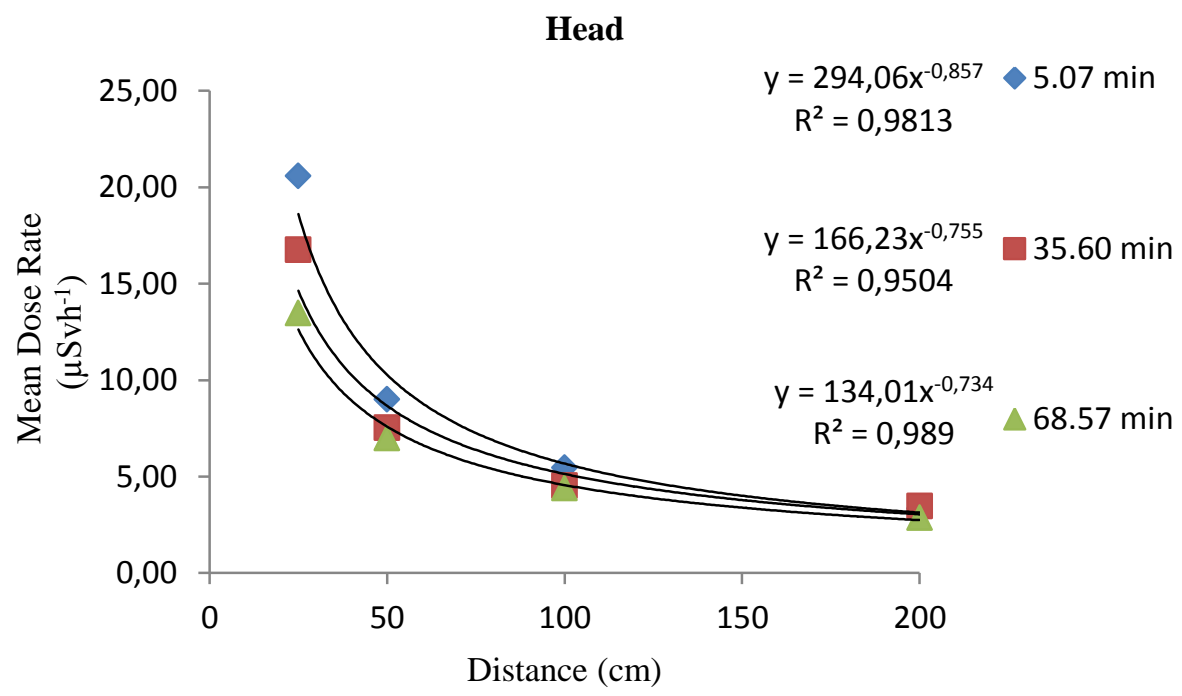

Figure 6. Mean dose rate by distance from patient head level at 5.07, 35.60 and 68.57 minute

Chest

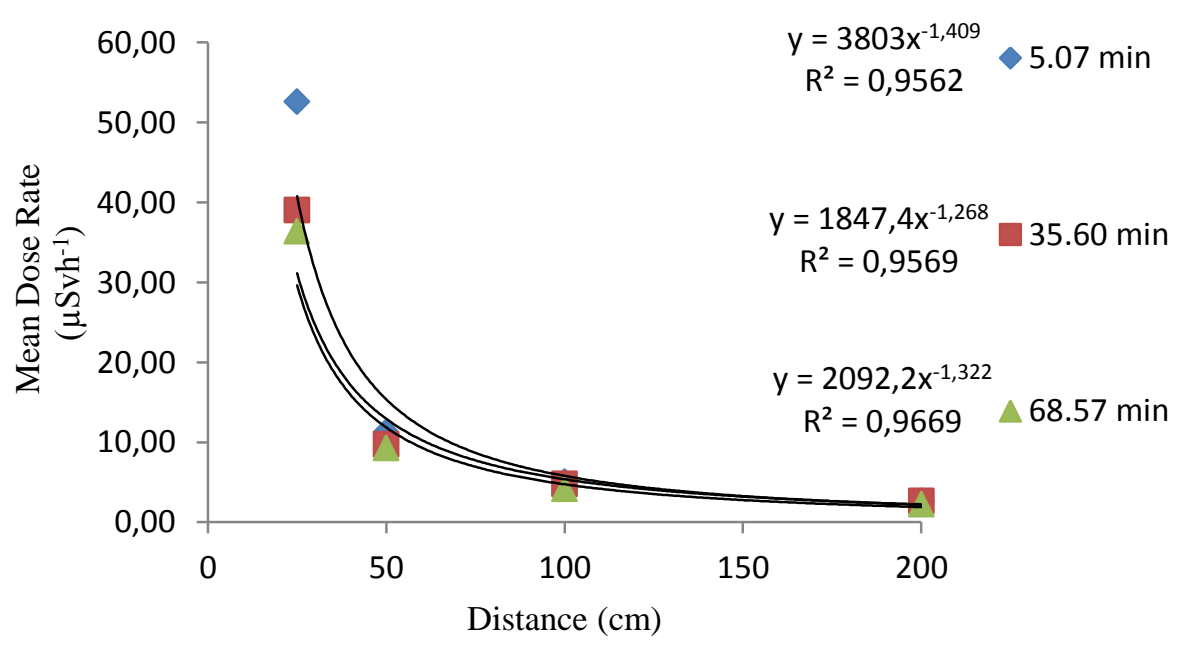

Figure 7. Mean dose rate by distance from patient chest level at 5.07, 35.60 and 68.57 minute 


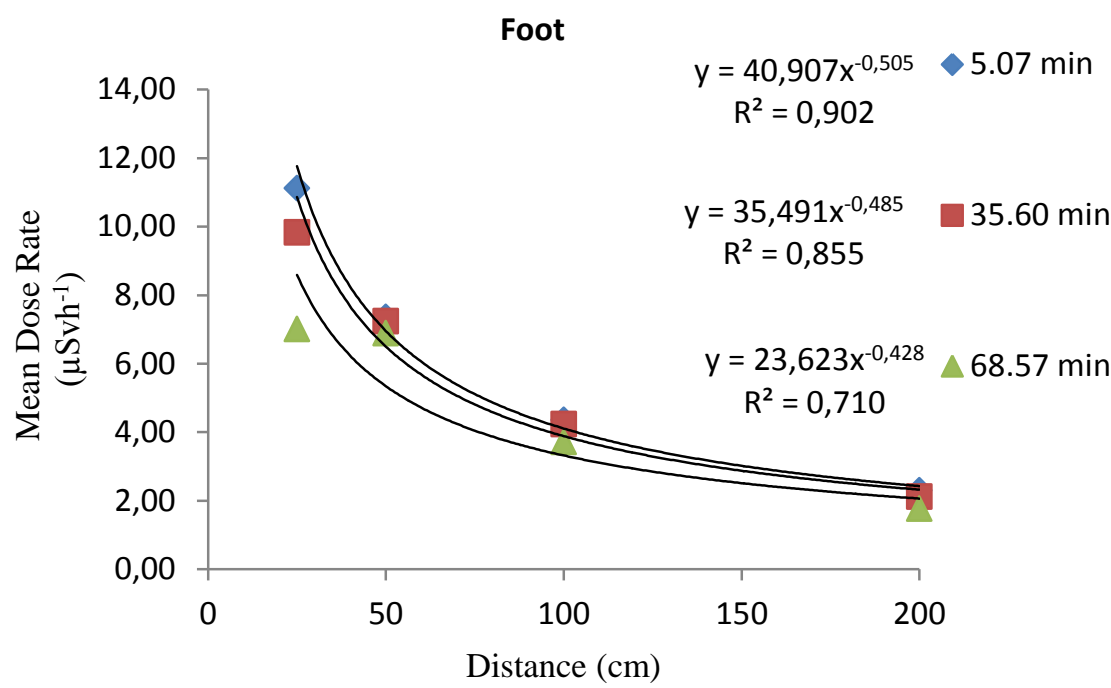

Figure 8. Mean dose rate by distance from patient foot level at 5.07, 35.60 and 68.57 minute

The radiation dose rate from $\mathrm{Tc}-99 \mathrm{~m}$ injected patients was measured by Günay et al. in 2019 [13]. In this study, radiation dose rate was determined at different distances and at different times after the injection of radiopharmaceuticals to cardiac patients. In our study, radiation dose rate was determined after injection of radiopharmaceutical in kidney patients. In both studies, gamma- transmitting Tc-99m was used as radiopharmaceutical. In the study performed by Günay et al., while the patient was injected with $391 \mathrm{MBq}$ of radioactive material, $168 \mathrm{MBq}$ was injected in this study. Therefore, for similar distance and time, the radiation dose rate in our study was lower than that of Günay et al.(Table 5).

Table 5. Comparison of mean dose rate and normalized mean dose rate by other studies

\begin{tabular}{|c|c|c|c|c|c|}
\hline $\begin{array}{l}\text { Location } \\
\text { Level }\end{array}$ & $\begin{array}{l}\text { Distance from } \\
\text { patient }(\mathrm{cm})\end{array}$ & $\begin{array}{c}\text { Time after the } \\
\text { injection } \\
\text { (minute) }\end{array}$ & $\begin{array}{c}\text { Mean Dose } \\
\text { Rate } \\
\left(\mu \mathrm{Svh}^{-1}\right)\end{array}$ & $\begin{array}{c}\text { Normalized Mean } \\
\text { Dose Rate } \\
\left(\mu \operatorname{Svh}^{-1} \mathrm{MBq}^{-1}\right)\end{array}$ & Reference \\
\hline \multirow{3}{*}{ Head } & \multirow{3}{*}{100} & 7.6 & 8.81 & 0.022 & \multirow{3}{*}{ [13] } \\
\hline & & 36.5 & 7.72 & 0.019 & \\
\hline & & 66.4 & 7.51 & 0.019 & \\
\hline \multirow{3}{*}{ Head } & \multirow{3}{*}{100} & 5.07 & 5.47 & 0.033 & \multirow{3}{*}{ This Study } \\
\hline & & 35.60 & 4.53 & 0.027 & \\
\hline & & 68.57 & 4.41 & 0.026 & \\
\hline \multirow{3}{*}{ Chest } & \multirow{3}{*}{100} & 7.6 & 9.07 & 0.023 & \multirow{3}{*}{ [13] } \\
\hline & & 36.5 & 7.93 & 0.020 & \\
\hline & & 66.4 & 7.83 & 0.020 & \\
\hline \multirow{3}{*}{ Chest } & \multirow{3}{*}{100} & 5.07 & 5.06 & 0.030 & \multirow{3}{*}{ This Study } \\
\hline & & 35.60 & 4.76 & 0.028 & \\
\hline & & 68.57 & 4.18 & 0.025 & \\
\hline \multirow{3}{*}{ Foot } & \multirow{3}{*}{100} & 7.6 & 8.43 & 0.021 & \multirow{3}{*}{ [13] } \\
\hline & & 36.5 & 7.01 & 0.018 & \\
\hline & & 66.4 & 6.87 & 0.017 & \\
\hline \multirow{3}{*}{ Foot } & \multirow{3}{*}{100} & 5.07 & 4.35 & 0.026 & \multirow{3}{*}{ This Study } \\
\hline & & 35.60 & 4.24 & 0.025 & \\
\hline & & 68.57 & 3.71 & 0.022 & \\
\hline
\end{tabular}




\section{Conclusion}

In this study, environmental radiation doses were determined in patients undergoing Tc-99m DMSA cortical renal scintigraphy. In this study, the radiation dose emitted by the patient at different times after Tc-99m injection was measured at different distances from the patient. As a result of this study, the mean radiation dose at 5.07, 35.60 and 68.57 minutes after injection was found to be $5.06 \mu \mathrm{Svh}^{-1}, 4.76 \mu \mathrm{Svh}^{-1}$ and $4.18 \mu \mathrm{Svh}^{-1}$ at $100 \mathrm{~cm}$ distance from the patient's chest level. At a distance of $200 \mathrm{~cm}, 5.07,35.60$ and 68.57 minutes after the injection the radiation dose spread to the environment was found to be $2.65 \mu \mathrm{Svh}^{-1}, 2.65$ $\mu \mathrm{Svh}^{-1}$ and $2.24 \mu \mathrm{Svh}^{-1}$.

Radiation professionals should be exposed to less than $10 \mu \mathrm{Sv} \mathrm{h}^{-1}$ dose rate [14]. But for public, this exposed radiation rate is $1 \mu \mathrm{Sv} \mathrm{h}^{-1}$.

According to the results obtained from this study, radiation professionals should stay at least $50 \mathrm{~cm}$ away from the patient. For public, these distances should be longer. It was also emphasized that the permissible dose rate for the public $\leq 1 \mu \mathrm{Sv} \mathrm{h}{ }^{-1}$ at 2 $\mathrm{m}$ distance from the patient cannot be fulfilled 68 minute after the start of Tc-99m injection.

\section{Acknowledgement}

Authors would like to thank the Kartal Dr. Lütfi Kirdar Education and Research Hospital and Istanbul Okan University Hospital for cooperation in this study.

\section{References}

[1] Boschi, A., Martini, P., Pasquali, M., \& Uccelli, L. Recent achievements in Tc-99m radiopharmaceutical direct production by medical cyclotrons. Drug development and industrial pharmacy, (2017), 43(9), 1402-1412.

[2] Piers, D. A., Kosterink, J. G., \& Meijer, S., Renal handling of technetium-99m DMSA: evidence for glomerular filtration and peritubular uptake. Journal of nuclear medicine: official publication, Society of Nuclear Medicine, (1989), 30(7), 1219-1223.

[3] Arnold, R. W., Subramanian, G., McAfee, J. G., Blair, R. J., \& Thomas, F. D., Comparison of 99mTc complexes for renal imaging. Journal of Nuclear Medicine, (1975), 16(5), 357-367.

[4] Chervu, L. R., \& Blaufox, M. D., Renal radiopharmaceuticals - an update. In Seminars in nuclear medicine, (1982), Vol. 12, No. 3, pp. 224245).
[5] Mendichovszky, I., Solar, B. T., Smeulders, N., Easty, M., \& Biassoni, L. Nuclear medicine in pediatric nephro-urology: an overview. In Seminars in nuclear medicine, (2017, Vol. 47, No. 3, pp. 204228, doi.org/10.1053/j.semnuclmed.2016.12.002

[6] Snodgrass, W. T., Shah, A., Yang, M., Kwon, J., Villanueva, C., Traylor, J., ... \& Bush, N. C. Prevalence and risk factors for renal scars in children with febrile UTI and/or VUR: a cross-sectional observational study of 565 consecutive patients. Journal of pediatric urology, (2013), 9(6), 856-863.

[7] Goswami, R., Bal, C. S., Tejaswi, S., Punjabi, G. V., Kapil, A., \& Kochupillai, N. Prevalence of urinary tract infection and renal scars in patients with diabetes mellitus. Diabetes research and clinical practice, (2001). 53(3), 181-186.

[8] MacKenzie, J. R., DMSA-the new 'gold standard', Nuclear Medicine Communications, (1990): 725726.

[9] Ajdinović, B., Jauković, L., Krstić, Z., \& Dopuda, M. Technetium-99m-dimercaptosuccinic acid renal scintigraphy in children with urinary tract infections. Hellenic journal of nuclear medicine, (2006), 9(1), 27-30.

[10] Lassmann, M., Biassoni, L., Monsieurs, M., Franzius, C., \& Jacobs, F., The new EANM paediatric dosage card. European journal of nuclear medicine and molecular imaging, (2007). 34(5), 796798.

[11] Baert, Albert L. Diagnostic nuclear medicine. Springer Science \& Business Media, 2006..

[12] Bennett, Paige A., and Umesh D. Oza. Diagnostic Imaging: Nuclear Medicine E-Book. Elsevier Health Sciences, 2015.

[13] Günay, O., et al. "Determination of radiation dose from patients undergoing Tc-99m Sestamibi nuclear cardiac imaging." International Journal of Environmental Science and Technology (2019): 1-8.

[14] Demir M Radiobiological effects, protection of the patient, protection of caregivers, protection of those around the patient and the environment. Nucl Med Semin (2015) 3:171-179. https ://doi. org/10.4274/nts.0026 